\title{
The Objectives of Sustainable Development and the Academy
}

\section{Jorge Cosme Casulo}

Department Economy and the Health, Ability of Medicine No. 1 University of Medical Sciences, Santiago, Cuba

\section{Email address:}

jcosme $a$ infomed.sld.cu

\section{To cite this article:}

Jorge Cosme Casulo. The Objectives of Sustainable Development and the Academy. Social Sciences. Vol. 7, No. 5, 2019 , pp. 68-72. doi: 10.11648/j.sr.20190705.13

Received: July 24, 2019; Accepted: September 22, 2019; Published: October 25, 2019

\begin{abstract}
The evaluation and the report on the results reached with the Objectives of Development of the Millennium up to 2015, allowed a projection of more reach through the Objectives of Sustainable Development up to 2030, with the deepening in these objectives and their respective tasks, where each one is not integrated alone for their attainment, but also in their sustainability. In this article it is emphasized how in this calendar the university is inserted in the first place, for its important list in the formation and overcoming of the human capital and in the investigation, and he/she also stands out its necessary relationship with the communities, where the university extension and the local development constitute environments for the indispensable complement in its social function in an integral way, where on this important aspect he/she intends the amplification of the universe of activities to carry out, as well as the necessity to include in the curricula of the different university careers and in the investigations, the Objectives of Sustainable Development.
\end{abstract}

Keywords: Sustainable, Academy, Universities, University Extension, Local Development

\section{Introduction}

The former General Secretary of United Nations, BanKiMoon, in the Report of the 2015 of the Objectives of Development of the Millennium referred the following: [1]

The world mobilization after the Objectives of Development of the Millennium (ODM) it has generated the movement against the most successful poverty in the history. The momentous commitment that the leaders of the world assumed in the year 2000 of "not to scant efforts to liberate our fellow men, men, women and children of the abject and dehumanizing conditions of the extreme poverty", it was captured in a mark of inspiring work of eight objectives, and later in practical steps of wide spectrum that have allowed people from all over the world to improve their lives and their future perspectives. The ODM helped to that escaped of the extreme poverty more than a thousand million people, to combat the hunger, to facilitate that more girls attended the school that never before, and to protect our planet. They generated new and innovative collaborations, they impelled the public opinion and they showed the immense value to establish ambitious objectives. When locating to people and their immediate necessities in a first plane, the ODM reconfigured the taking of decisions so much in developed countries as in countries in development.

In spite of the remarkable achievements, I am deeply aware that the inequalities persist and that the progress has been unequal.

[...] We have to face the roots of the causes and to make more to integrate the economic, social and environmental dimensions of the sustainable development. The emergent calendar for the development after 2015 that it will include a group of Objectives of Sustainable Development, struggles to reflect these lessons, to build on the base of our successes, and to guide together and firmly to all the countries toward a more prosperous, sustainable and equal world.

The Objectives of Sustainable Development are a commitment signed by all the countries members of the United Nations (UN) that contemplates different periods of execution and evaluation.

1. In this respect, the states members of the UN approved the ODS for the period 2016-2030, in a more comprehensive environment and with more experience on the topic that you/they understand 17 objectives and 169 goals. Next they stand out the objectives:

1. To put an end to the poverty in all their forms in the 
entire world.

2. To put an end to the hunger, to achieve the alimentary security and the improvement of the nutrition and to promote the sustainable agriculture.

3. To guarantee a healthy life and to promote the wellbeing for all in all the ages.

4. To guarantee an inclusive, equal education and of quality and to promote learning opportunities during a lifetime for all.

5. To achieve the equality between the goods and empower all the women and girls.

6. To guarantee the readiness of water and their sustainable administration and the reparation for all.

7. To guarantee the access to an affordable, sure, sustainable and modern energy for all.

8. To promote the sustained economic growth, inclusive and sustainable, the full and productive employment and the decent work for all.

9. To build infrastructures resilientes, to promote the inclusive and sustainable industrialization and to foment the innovation.

10. To reduce the inequality in and among the countries.

11. To get that the cities and the human establishments are inclusive, sure, resilientes and sustainable.

12. To guarantee consumption modalities and sustainable protection.

13. To adopt urgent measures to combat the climatic change and their effects.

14. To conserve and to use in sustainable form the oceans, the seas and the marine resources for the sustainable development.

15. To protect, to reestablish and to promote the sustainable use of the terrestrial ecosystems, to make a sustainable ordination of the forests, to fight against the desertification, to stop and to revert the degradation of the lands and to put control to the loss of biological diversity.

16. To promote peaceful and inclusive societies for the sustainable development, to facilitate the access to the justice for all and to create effective, responsible and inclusive institutions at all the levels.

17. To strengthen the execution means and to revitalize the world alliance for the sustainable development.

\subsection{Problem of Investigation}

Insufficient linking of the Academy to the processes of execution of the Objectives of Sustainable Development.

\subsection{Hypothesis}

If a coherent work was achieved between the Academy and the ODS, the contribution to its results serious chord with the purposes of the same ones.

\subsection{Prospective Impacts}

Scientific: Besides applying the knowledge of the science, a feedback that will allow enlarging its integral focus will exist.

Economic and social: Contribute to the increment of the employment and economic growth, what will redound in the relief of the poverty and the social well-being.

\section{Development}

\section{Science, knowledge and development}

"As the problems that face has many variables, the classic focus of the science stops to work and a more integral boarding is required". [2]

Keeping in mind the economic conditions and the social variables, the development scientific-technician is a social fact and it is necessary to transform it into culture.

The strategies of social communication should be developed assisting to the cultural conditions of each context, to be able to arrive to the conscience of people and that he/she becomes knowledge.

Already from this moment the academy should carry out a decisive function for the sake of socializing the knowledge, what becomes indispensable to approach the different ones problematic in the mark of the complexities of the current world.

The fourth objective of the ODS picks up guaranteeing an inclusive, equal education and of quality promoting learning opportunities during a lifetime for all, and enter its tasks for the 2020 it is included increasing at world level substantially the number of available scholarships for the countries in development, in particular the less early ones, the small insular states in development and the countries of Africa, so that its students can enroll in programs of superior studies in developed nations and others in development, what includes programs of professional formation, technical, scientific programs, of engineering and of technology of the information and the communications.

On the other hand, in most of the objectives, the academy, through the investigations and of the insert in the integral development of the countries, it can make an important contribution.

\subsection{The Local Development}

The topic of the local environment and their development has been, it is and it will be very important, so much stops its communities as for all the geographical structures, until the country like such. For it, for some time one comes treating the topic in the different spaces on the part of organisms, organizations and international agencies, as well as for academic and political personalities of different countries.

Poking in the time - not very distant -, in 1968 the Project began On the Human Condition that the development concept evolved when not considering it alone from the satisfaction of the material necessities, but as a process to obtain the integral well-being of the populations, on the base of the necessary relationship with its environment, where the individuals could deploy all their potentialities.

Later on, this initiative was picked up as valid in the report of the Club of Rome in 1972, recognizing it as the non alone 
change of the quantitative thing, but besides the qualitative aspects, for all the human beings in any of its geographical location.

In 1975, some European sectors, through their report "What to make? "did they emphasize in the development like an integral concept, where the human being and the satisfaction of their necessities constitute the supreme objective.

Then, in 1992, Colbset to the [3] they sentenced: "The development, in an everything, is an integral cultural process, rich in values that it embraces the natural means, the social relationships, the education, the production, the consumption and the well-being."

In the decades of the 80 and the 90 , some international organisms were pronounced on the topic, making a call and pointing out some rules in the international scenario, among those that stood out the Declaration on the Development (UN-1986), the Adjustment with Human Face (Fund of the United Nations for the Childhood-1987), the First Report on the Human Development (it Programs of the United Nations for the Development-1990), the Obtaining of the Social Justness (Economic Commission for Latin America and the Caribbean-1992), the Summit on the Social Development (UN-1990), all that had their colophon with The Objectives of Development for the Millennium (UN-2000).

Diverse academics have left captured, in their conferences and publications, proposals and actions carried out in function of the local development.

The Doctor in Economic Sciences and President of the Latin American Net of Universities for the Social Emprendedurismo [REDUnES], Bernardo Kliksberg, [4] maybe it is one of the academics with more publications on the topic, in which approaches important aspects related with the environmental surveillance, the development of the vulnerable populations, the creation of action capacities and managerial abilities, the promotion of alliances among the managerial thing and the public politicians, the active participation of the youths and the paper of the university.

Tortosa [5] it described that they should be kept in mind the dimensions that the communities consider important, the necessity to build indicators that you/they respond at the local, family and personal levels; the overcoming of the human resources and the local alliances with national and international organizations; it also defended with force that it is always possible to carry out something in the local environment. Also, Rodriguez's concepts can be summarized Gutierrez [6] on the rural youth's incorporation, the endogenous values, the social dialogue and the function of the university in the formation of the applied investigation.

On the other hand, Núñez Rodriguez [7] it highlights the establishment of the dialogue intercultural between the local knowledge and the universal one, to take advantage of their strengths, with a posture of synergism of the human knowledge.

The formation of the professionals that you/they participate in the programs of rural development (educational and technologists of the agriculture) in the Latin American countries, he/she is immersed in a series of complexities and annoyances. These professionals, as constructors of a society, in their majority reproduce without pause and unconsciously the modern knowledge, debtors of the western culture. However, the contexts where they exercise their labor action they exhibit a great wealth accumulated in the wisdom of the towns that are ignored by the entities involved in the functions inspectors.

The Latin American Agency of Information, in an article on the social economy and solidary, [8] he/she leaves established some basic elements for the development of the local environment, as the woman's equality, the establishments of alliances through synergies and the conversion in a collective fellow on the base of the community vision.

The experiences and good resulting practices of the projects of development local carried out in the Republic Of the Dominican Republic and the Republic of Haiti, [9-11] they are an example of what one can make in that address.

Among the activities developed under the premise of "to know to make", in the first place it has been the training of the human resources, the synergy with other projects, the exchange of experiences, the woman's active participation, by means of the creation of groups of work of local development and the use of the cultural traditions.

\subsection{The University}

Although in the whole related process reference is made previously, in a way or other, to the paper of the university in the endowment of integral knowledge, like a road of contributing to that development; that social responsibility one has come reflecting lately with bigger emphasis and precision.

In that address, different spaces have arisen in the own universities, investigation centers, nets and countries, as well as in national, regional, world events, where, besides the call, they have been built and proposed action lines.

It is necessary to highlight, among them, the Regional Conference of Superior Education (2008), the Conference Integrated Latin American University and the Population's Health (2008), the I World Forum of Agencies of the Local Development (2011), the World Conference On Decisive Social of the Health (2011), the II World Forum On Local Economic Development (2013) and the IX International Congress of Superior Education (2014), those that have been important tribunes to impel the process.

The paper of the universities is basic as strategic ally, to provide of knowledge and good administration practices that point to the development of such concrete activities as the creation of near university branches to the towns, where they are considered the local necessities of group with the communities, and the integration of strategies, in those that it is summoned to the participation of all the actors and it is articulated to the international cooperation.

In this general context, the Union of Universities of Latin America and of the Caribbean (UDUAL) he/she has come carrying out a meritorious work, for what has been 
constituted in an organ of advanced, carrying out important encounters with very defined strategies, summoning and integrating different actors and articulating to the process to the international cooperation.

Having a potential of more than 200 affiliated universities and contained in regions, the UDUAL has gone maturing in a progressive way in its to work, until proposing the creation of a Latin American Net and of the Caribbean on the Linking of the University to the processes of the Development Local, [10-12] what will surely constitute an agglutinative element, when propitiating the sustentabilidad of the process in the time, since in its work slopes it figures favoring the transformations of the universities, so that these they are efficient for the economic, social, cultural and technological development of each country and region. Plus recently it concerted an encounter for the analysis of the strategic convergence between the ODS and the university.

The Dr. Roberto Escalante Semerena, general secretary of the UDUAL, outlined a great challenge: "It is necessary to think how the community is linked with the University; if this is achieved we will organize the university otherwise". [13]

The experience of the University of Pinegrove of the River, Cuba, creator of the Center of Strategic Administration of the Local Development (GEDEL) [14], the one that starting from the scientific investigation, it facilitated the necessary tools by means of avove courses, graduates and investigation topics in masters and doctorates.

Another outstanding aspect of this University is the creation of Municipal University Centers, what facilitates even more the approach to the communities, with its respective feedback.

The Economic Commission for Latin America and the Caribbean (ECLAC) [15], he/she made a call to the Universities, together with other factors to their active participation in the attainment of the Objectives of Sustainable Development, also elaborating a methodological guide as contribution to the program elaboration adapting it to the characteristics of each country.

It is not enough to think that the university has to be related with its environment, it is necessary to be centered on what it consists that relationship, who they are participating in this context and which the most effective strategy is for embracer environment and actors.

The linking university-society requires today different focuses that can muter from a paradigm assistance to an environment of mutual learning's, and face the new challenges caused by the economic, social and cultural changes of the XXI century.

The other aspect that should be kept in mind is that of the university extension, where the youths are the main characters.

In this environment, the ODS up to the 2030 becomes a programmatic platform, in which all the aspects related with the integral development are inserted, where both they are supplemented for the strategy and the action.

\section{Conclusions}

The Objectives of Sustainable Development constitute the biggest challenge that has intended the Organization of the United Nations, with the approval of all the states members, where it should prevail the political will and the efficiency, the change of paradigms in this XXI century of the Academy, represented by its universities and investigation centers, will carry out an important function in the attainment of those objectives with successful results.

\section{Recommendations}

The universities will elaborate a program strategic chord to the characteristics of their territories that can give exit the proposed objectives the decentralization it should be valued with university centers or university branches toward the Municipalities, to enlarge the range of action of university extension, as well as to include the ODS in the curriculum of the different careers and of the investigations, to achieve bigger knowledge and premeditation.

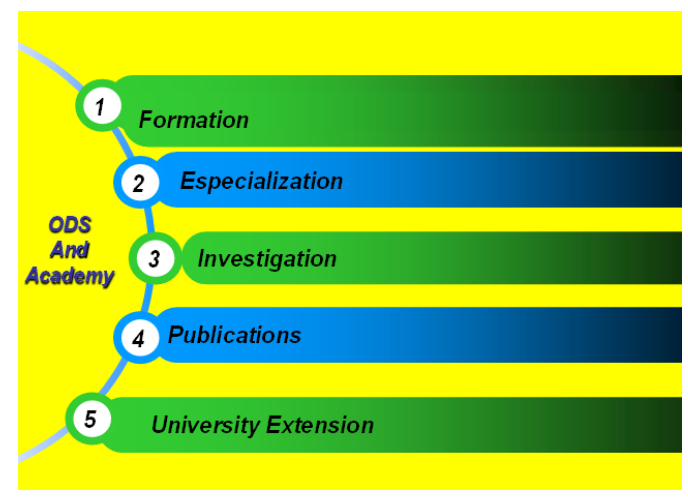

Figure 1. Pillars linking Academy and the ODS.

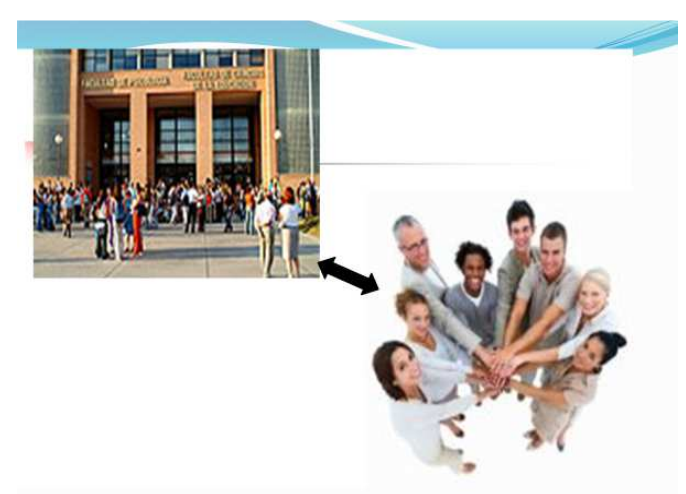

Figure 2. Community projection of the Academy.

\section{References}

[1] United Nations. Objectives of Development of the Formless Millennium 2015. New York: UN; 2015 [mentioned 16/01/2017]. Available in: http://www.un.org/es/millenniumgoals/pdf/2015/mdg_2015_s _summary_web.pdf 
[2] Pérez Martinez A. Agustin Lage: Science, knowledge and development. Health Life. 2013 Nov. [mentioned 16/01/2017]. Available

http://www.saludvida.sld.cu/entrevistaonline/2013/11/01/agust in-lage-science-knowledge-and-development

[3] Meadows DH, Randers J, Meadows DL. Beyond the limits of the growth. Madrid: Aguilar; 1992.

[4] Kliksberg B. social Capital and culture, strategic keys of the development. ECLAC have. 1999 Dec. [mentioned 16/01/2017]; 69. Available in: http://www.mincultura.gov.co/areas/fomentoregional/Documents/CapitalSocialyCultura_Kliksberg_1999.p df

[5] Tortosa JM. It programs Interdisciplinary of Population and Sustainable Local Development. Cuenca: University of Cuenca; 1999.

[6] Rodriguez Gutierrez Manual F. of Local Development. Gijon: Trea; 1999.

[7] Núñez J. Knowledge and Education. A look from the rural cultures. Have Digital Rural Economy. 2004 [mentioned 16/01/2017]; 12 (2). Available in: http://educación.upa.cl/revistaerural/erural.htm

[8] Latin agency of Information. Social economy and feminist solidary-economy. I remove, Ecuador, 2008 - 2013. I remove: ALAI; 2013. http://alainet.org
[9] Cosme J, Suriel OR, Omen R. Building Municipalities for the Health and the Development. Sacred Domingo: Editorial Serrallés; 2004.

[10] Union of Universities of Latin America and the Caribbean. Proposal Project of the Latin American Net and of the Caribbean it has more than enough Linking of the University to the Processes of Local Development. Mexico City: UDUAL; 2014-http://www.udual.org.

[11] Cosme J, The Shared Local Development for all and for allUniversity of Medical Sciences of Santiago from Cuba, Cuba2015.

[12] Cosme J, Strategy of Development Integral for the Republic of Haiti, University of Medical Sciences of Santiago from Cuba, Cuba,-2014.

[13] Autonomous National university of Nicaragua. Inform Seminar-shop "The University and their social impact in the Community". Managua: UNITE; 2012 [mentioned 16/01/2017] Available: http://www.pàho.org/nic/index.php

[14] Magazine OFFERS, $2019 \quad-\quad$ www.ofertas.cu, facebook.com/ofertas.cu

[15] To three years of the beginning of the ODS - CEPAL/Nations United-2019. 